Pesq. Vet. Bras. 30(12):1036-1042, dezembro 2010

\title{
Intoxicação por Brachiaria spp. em bovinos no Mato Grosso do Sul ${ }^{1}$
}

\author{
Roosevelt I.C. Souza ${ }^{2}$, Franklin Riet-Correa ${ }^{3}$, Karine B. Brum ${ }^{4}$, Carlos Eurico \\ Fernandes ${ }^{4}$, Marcos Barbosa-Ferreira ${ }^{4}$ e Ricardo A. Amaral de Lemos ${ }^{5}$
}

\begin{abstract}
Souza R.I.C., Riet-Correa F., Barbosa-Ferreira M., Brum K.B., Fernandes C.E. \& Lemos R.A.A. 2010. [Brachiaria spp. poisoning in cattle in Mato Grosso do Sul, Brazil.] Intoxicação por Brachiaria spp. em bovinos no Mato Grosso do Sul. Pesquisa Veterinária Brasileira 30(12):1036-1042. Departamento de Medicina Veterinária, Faculdade de Medicina Veterinária e Zootecnia, Universidade Federal de Mato Grosso do Sul, Av. Senador Filinto Müller 2443, Cx. Postal 549, Campo Grande, MS 79070-900, Brazil. E-mail: carvalhomv6@hotmail.com

The epidemiology, clinical signs and pathology of 29 outbreaks of spontaneous poisoning by Brachiaria spp. in beef cattle, which occurred from March 1996 to November 2009, in the state of Mato Grosso do Sul, were retrospectively studied. For this, the files of the Veterinary Pathology Laboratory at the Federal University of Mato Grosso do Sul were reviewed. Outbreaks occurred at different times of the year, including dry and rainy seasons. While photosensitization was the main clinical sign in cattle from 24 out of 29 outbreaks, in five of them the main clinical sign was progressive wasting, without photosensitization. Eleven outbreaks of photosensitization occurred in pastures of Brachiaria decumbens, two in mixed pastures of $B$. decumbens and $B$. brizantha, and one in $B$. brizantha. In 10 outbreaks the species of Brachiaria was not informed. Morbidity ranged from $0.2 \%$ to $50 \%$, and fatality rates were between $44.4 \%$ and $100 \%$. In cases of photosensitization brisket edema was the most frequent clinical sign observed. Dermatitis with thickened skin of the flank and perineal region, scar retraction of the ears, jaundice, ocular discharge, crusts in the eyes and ears, and ulceration of the ventral surface of the tongue were also observed. Nervous signs were observed in two cases and diarrhea in one. At necropsy the liver was enlarged, yellowish, with increased lobular pattern, and occasionally with depressed whitish areas. The kidneys were brownish and the urine dark. Upon histological examination of the liver the hepatocytes were swollen and vacuolized. Individual necrosis of hepatocytes, bile duct cell proliferation, biliary retention, and mild to moderate periportal fibrosis were also observed. In all cases foamy macrophages, most in groups, were observed mainly in the centrilobular region. In 21 cattle birefringent crystals were observed within the bile ducts. Five outbreaks of progressive wasting were observed in cattle grazing $B$. decumbens pastures. The main lesion was an enlarged yellowish liver. Histologic lesions were similar to those observed in cases of photosensitization. Birefringent crystals were observed in the liver of three cases, but foamy macrophages were found in all animals. It is concluded that $B$. decumbens is more toxic than $B$. brizantha and that the poisoning occurs at any time of the year. Nevertheless, research is still necessary to determine variations in the saponin content of Brachiaria species and the probable differences on susceptibility/ resistance to the poisoning of cattle of different ages, breeds and from different regions.
\end{abstract}

INDEX TERMS: Brachiaria spp., Brachiaria decumbens, poisonous plants, photosensitization, progressive wasting, ruminants, plant poisoning.

\footnotetext{
${ }^{1}$ Recebido em 12 de junho de 2010.

Aceito para publicação em 9 de agosto de 2010.

2 Mestrando em Ciência Animal, Universidade Federal do Mato Grosso do Sul (UFMS). Endereço particular: Rua Anhanguera 2015, Casa 4, Campo Grande, MS 79080-740, Brasil. *Autor para correspondência: carvalhomv6@hotmail.com

${ }^{3}$ Hospital Veterinário, Centro de Saúde e Tecnologia Rural (CSTR),
}

Universidade Federal de Campina Grande (UFCG), Patos, PB 58700-000, Brasil.

4 Departamento de Patologia, Centro de Ciências Biológicas e da Saúde (CCBS), UFMS, Av. Senador Filinto Müller 2443, Cx. Postal 549, Campo Grande, MS 79070-900.

${ }^{5}$ Departamento de Medicina Veterinária, Faculdade de Medicina Veterinária e Zootecnia Haroldo Sampaio (FAMEZ), UFMS, Campo Grande, MS. 
RESUMO.- Mediante a revisão dos arquivos das fichas de necropsia do Laboratório de Patologia Animal, Universidade Federal do Mato Grosso do Sul, foram estudados a epidemiologia, o quadro clínico e a patologia de 29 surtos de intoxicação por Brachiaria spp., ocorridos em bovinos de corte, no Mato Grosso do Sul, de março de 1996 a novembro de 2009. Os surtos ocorreram em todas as épocas do ano, tanto na seca quanto na chuva. Em 24 dos 29 surtos o principal sinal clínico foi a fotossensibilização e em cinco o principal sinal foi o emagrecimento progressivo. Dos 24 surtos de fotossensibilização, 11 ocorreram em pastagens de $B$. decumbens, dois em pastagens mistas de $B$. decumbens e $B$. brizantha, um em $B$. brizanthae em 10 surtos não foi informada a espécie de Brachiaria envolvida. A morbidade variou de $0,2 \%$ a $50 \%$ e a letalidade de $44,4 \%$ a $100 \%$. Nos casos de fotossensibilização o edema de barbela foi o sinal clínico mais encontrado em bovinos, seguido de dermatite com pele espessada no flanco e períneo, retração cicatricial auricular, icterícia, corrimento ocular. crostas auriculares e oculares, e ulcerações na parte ventral da língua. Em dois surtos foram observados sinais nervosos e em um, diarréia. Nas necropsias o fígado estava aumentado de tamanho, amarelado, com padrão lobular aumentado e, ocasionalmente, com áreas esbranquiçadas e deprimidas. Os rins estavam acastanhados e a urina escura. No exame histológico do fígado encontrou-se tumefação e vacuolização de hepatócitos, proliferação de células epiteliais dos ductos biliares, retenção biliar, fibroplasia periportal discreta ou moderada e infiltrado mononuclear periportal. Todos os casos de fotossensibilização apresentaram macrófagos espumosos no parênquima hepático e em 21 foram observados cristais birrefringentes nos ductos biliares. Cinco surtos com emagrecimento progressivo dos bovinos afetados foram diagnosticados em pastagens de $B$. decumbens. A principal lesão macroscópica foi o fígado aumentado de volume e amarelado. No estudo histológico, as lesões foram semelhantes às observadas nos casos de fotossensibilização, sendo que cristais refringentes nos ductos biliares foram observados em três animais. Conclui-se que $B$. decumbens é mais tóxica que $B$. brizantha e que a intoxicação ocorre, principalmente, em bovinos jovens nas diferentes épocas do ano. No entanto, pesquisas são necessárias para determinar as variações no conteúdo de saponinas litogênicas em Brachiaria spp. e as diferenças de resistência/susceptibilidade à intoxicação de bovinos de diferentes idades e raças em diferentes regiões.

TERMOS DE INDEXAÇÃO: Brachiaria spp., Brachiaria decumbens, plantas tóxicas, fotossensibilização, emagrecimento progressivo, ruminantes, intoxicação por planta.

\section{INTRODUÇÃO}

As espécies de Brachiaria são originárias da África Tropical e utilizadas como forrageiras, tendo se adaptado bem aos trópicos úmidos. Brachiaria decumbens foi introduzida pela primeira vez no Brasil em 1952 pelo Instituto de
Pesquisas Experimentais Agropecuárias do Norte (IPEAN), pertencente ao Ministério da Agricultura. B. decumbens cv Ipean se reproduzia por estolhos, motivo pelo qual se expandiu lentamente. Essa limitação foi superada quando em 1972 foram importadas da Austrália sementes de $B$. decumbens cv. Brasilisk de alto poder germinativo (Seiffert 1980). Os primeiros surtos de fotossensibilização em bovinos, em pastagens, ocorreram depois que essa variedade passou a ser consumida pelos animais (Camargo et al. 1976, Döbereiner et al. 1976, Nobre \& Andrade 1976, Schenk et al. 1983). Brachiaria brizantha cv. Marandú (capim mandacaru) foi lançado em 1983 pela Embrapa Gado de Corte e Embrapa Cerrados e gradualmente foi substituindo $B$. decumbens em grandes áreas (Seiffert 1980).

Inicialmente toxicidade de $B$. decumbens foi associada à presença de Pithomyces chartarum, mas posteriormente foi demonstrado que a intoxicação em ruminantes é causada por de saponinas esteroidais litogênicas presentes na planta (Cruz et al. 2000, 2001, Brum et al. 2007, Castro et al. 2009). Além da fotossensibilização, descreve-se, na intoxicação por $B$. decumbens, uma síndrome de emagrecimento progressivo, sem lesões de fotossensibilização (Riet-Correa et al. 2002)

O objetivo deste trabalho é fazer um estudo retrospectivo dos surtos espontâneos de intoxicação por Brachiaria spp. em bovinos, no Mato Grosso do Sul, diagnosticados de março de 1996 a dezembro de 2009 pelo Laboratório de Anatomia Patológica Animal da FAMEZ-UFMS.

\section{MATERIAL E MÉTODOS}

Foram estudados 29 surtos espontâneos de intoxicação por Brachiaria spp. diagnosticados de março de 1996 a dezembro de 2009 em bovinos no Mato Grosso do Sul. Os dados epidemiológicos, sinais clínicos e lesões macroscópicas foram coletados nos laudos de necropsia do Laboratório de Anatomia Patológica Animal (LAP), da Universidade Federal do Mato Grosso do Sul (UFMS). Dezessete bovinos intoxicados foram necropsiados por técnicos do LAP e 12 por Médicos Veterinários que atuam no campo. Cada necropsia correspondeu a um surto. Lesões histológicas foram estudadas em lâminas histológicas coradas pela hematoxilina-eosina (HE), já confeccionadas durante a ocorrência dos surtos, ou em novas lâminas confeccionadas durante a realização deste estudo para observações complementares.

\section{RESULTADOS}

Os surtos ocorreram de 1996 a 2009, em diversos municípios de diferentes regiões do Mato Grosso do Sul, incluindo Água Clara, Alcinópolis, Aquidauana, Bonito, Caarapó, Campo Grande, Cassilândia, Corumbá, Laguna Caarapã, Naviraí, Nioaque, Ribas do Rio Pardo, Rochedo, Santa Rita, Sidrolândia e Terenos.

A distribuição dos surtos por cada ano estudado encontra-se na Fig.1 e a distribuição mensal dos surtos ao longo dos 14 anos do estudo encontra-se na Fig.2.

Um surto ocorreu em bezerros de 30-60 dias de idade, um em bezerros lactentes de até seis meses, nove surtos ocorreram em bovinos de 7-12 meses (incluindo dois carac- 


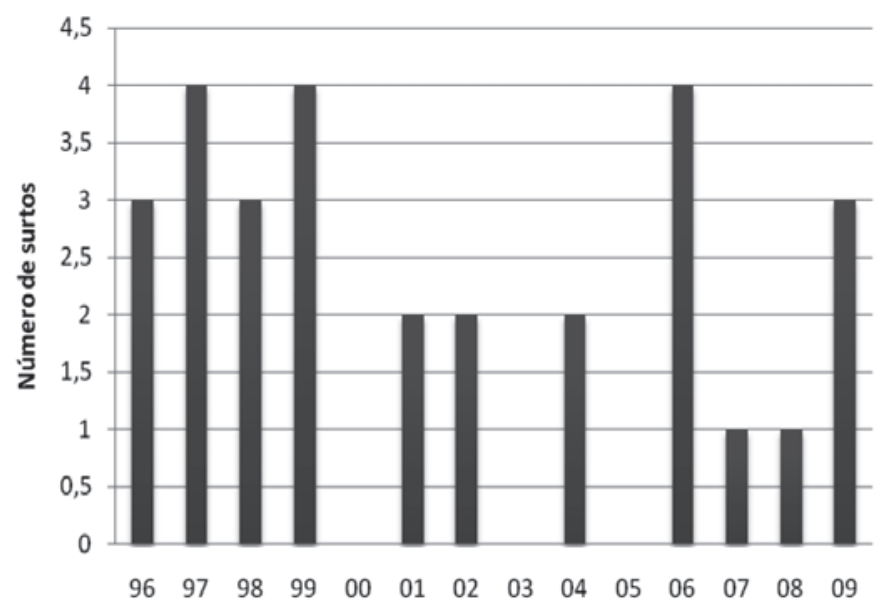

Fig.1. Número de surtos de intoxicação por Brachiaria spp. em bovinos no Mato Grosso do Sul de 1996 a 2009.

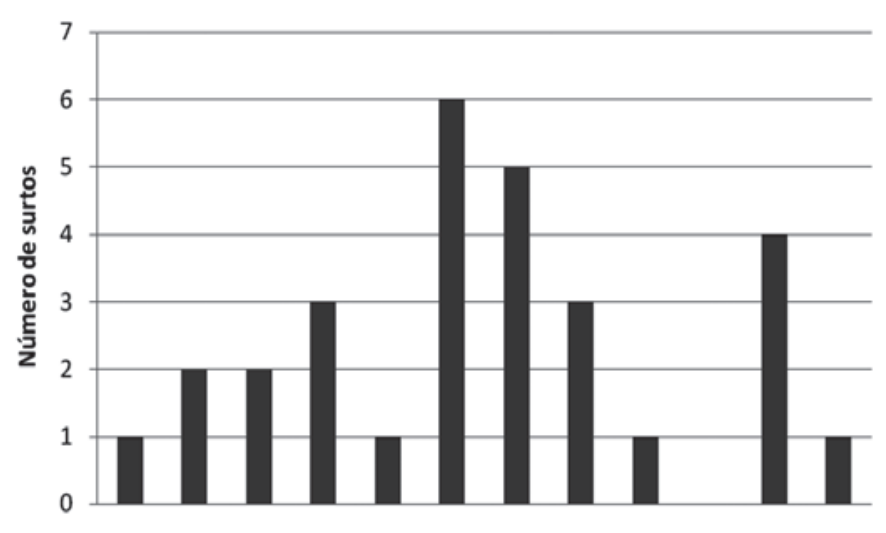

JAN FEV MAR ABR MAI JUN JUL AGO SET OUT NOV DEZ

Fig.2. Número de surtos de intoxicação por Brachiaria spp. em bovinos nos meses de 1996 a 2009 no Mato Grosso do Sul.

terizados por emagrecimento progressivo), cinco em bovinos de 13-18 meses, sete em bovinos de 19-24 meses e cinco em bovinos maiores de 31 meses (incluindo três surtos caracterizados por emagrecimento progressivo). Em bovinos de 25-30 meses não foi observado nenhum surto.

Dos 24 surtos de fotossensibilização encaminhados ao LAP dentro do período estudado, 11 acorreram em pastos exclusivamente de $B$. decumbens, dois em pastagem mista de Brachiaria decumbens e $B$. brizantha, um em pastos de $B$. brizantha e em 10 surtos não foi informada a espécie de Brachiaria spp. que formava a pastagem. Os cinco surtos de emagrecimento progressivo ocorreram em pastagens de $B$. decumbens.

Dois surtos ocorreram em bezerros. Em um, que afetou bezerros lactentes de até seis meses de idade em $B$. brizantha, a morbidade foi de $56 \%$ e a letalidade de $35 \%$. Outro surto, em B. decumbens, afetou bezerros de 30-60 dias e teve morbidade de $13 \%$ e letalidade de $33 \%$. Nos demais surtos de fotossensibilização a morbidade variou entre $0,02 \%$ a $18 \%$ e a letalidade de $26,67 \%$ a $100 \%$. Nos surtos de emagrecimento progressivo não havia informações nas fichas sobre frequência da enfermidade.
Em 24 surtos de intoxicação por Brachiaria spp. os principais sinais clínicos foram de fotossensibilização hepatógena que se caracterizava por edema de barbela em 15/24 casos $(62,5 \%)$, dermatite com pele espessada e formação de crostras no flanco e períneo em 11/24 casos (45\%); retração cicatricial auricular em $8 / 24$ casos (36\%), icterícia em $7 / 24$ casos (32\%); crostas oculares e auriculares em 4/ $24(18 \%)$ e ulcerações na parte ventral da língua em 5/24 (21\%). Foram observados, também, edema das orelhas, corrimento ocular, salivação, inquietação, prurido e busca pela sombra. Em dois surtos foram observados sinais nervosos incluindo incoordenação, paresia dos membros anteriores e posteriores, andar cambaleante, opistótono e movimentos de pedalagem. Em um surto, em bovinos de 1,5 anos de idade, foi observada diarréia. Houve cinco surtos de intoxicação por Brachiaria decumbens em animais sem fotossensibilização, que apresentaram emagrecimento progressivo, apatia, anorexia e caquexia.

Quanto aos achados de necropsia, hepatomegalia foi observada em 14/24 casos (58\%); fígado amarelado em $13 / 24$ casos (54\%); fígado com padrão lobular aumentado em $7 / 24$ casos (29\%); ulcerações na parte ventral da língua em $5 / 24$ casos (21\%); rins acastanhados e urina escurecida em $4 / 24$ casos (17\%) e fígado com áreas esbranquiçadas deprimidas em $3 / 24$ casos (12\%). Nos casos de emagrecimento progressivo a única lesão informada foi o fígado aumentado de volume e amarelado.

Na histopatologia do fígado não foram observadas diferenças evidentes entre os casos de fotossensibilização e os de emagrecimento progressivo. Todos os 29 casos apresentaram algum grau de tumefação e vacuolização de hepatócitos (Fig.3) e graus variáveis de fibrose periportal. Havia necrose individual de hepatócitos (Fig.3) em 18 casos, hiperplasia discreta ou moderada de células epiteliais dos ductos biliares em 21, retenção biliar em 17 e infiltrado mononuclear periportal em 26 . Em 22 casos havia macrófagos espumosos (Fig.4), distribuídos preferencialmente na área centrolobular. Em 18 casos foram observados cristais birrefringentes (Fig.5) ou imagens negativas desses cristais no interior dos ductos biliares. Os macrófagos, medindo de 14-70 $\mu \mathrm{m}$, apresentavam-se individualmente ou formando grupos de 3-50 macrófagos, com citoplasma finamente vacuolizado e núcleo central ou marginalizado. Células gigantes multinuceladas com núcleos distribuídos no citoplasma ou na periferia foram também observadas. No único caso em que ocorreu diarréia foram observados taquizoítos e macrogamontes de Eimeria sp. nos cortes do intestino. Nos cortes histológicos do sistema nervoso dos animais com sinais nervosos não foram observadas lesões significantes. Em outros órgãos não foram observadas lesões significantes com exceção da presença de macrófagos espumosos em alguns linfonodos (que não foram enviados em todos os casos para exame histológico). Em somente dois casos de emagrecimento progressivo foram examinados cortes de intestino delgado, sem que fossem observados macrófagos espumosos. Tanto macrófagos espumosos no fígado quanto cristais nos ductos 


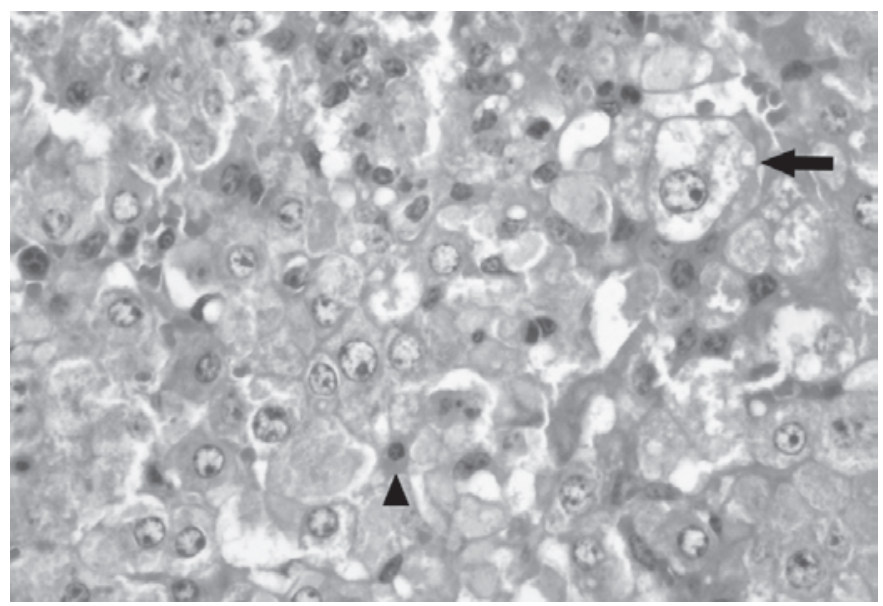

Fig.3. Hepatócitos marcadamente tumefeitos e vacuolizados (seta), e necrose individual de hepatócitos (cabeça de seta), na intoxicação por Brachiaria decumbens em bovino. HE, obj.40x.

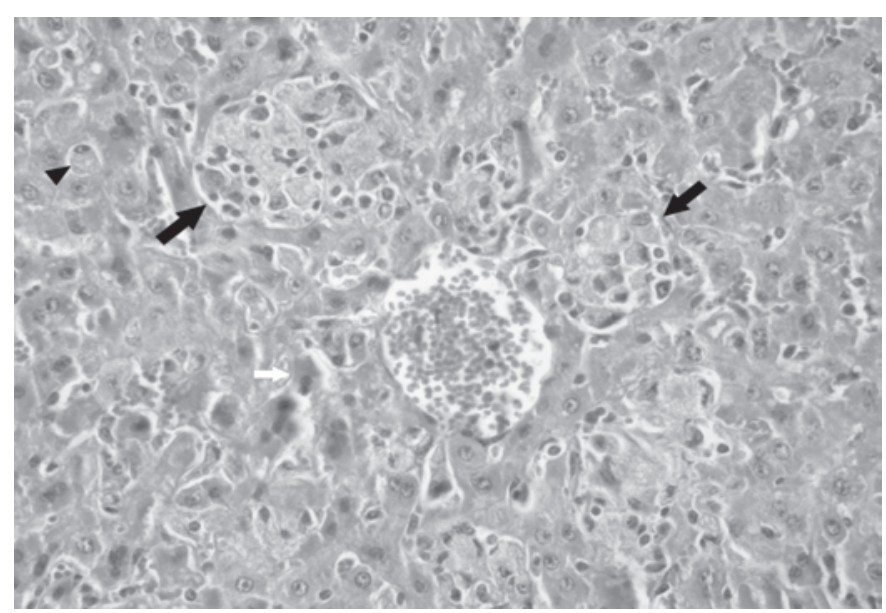

Fig.4. Grupos de macrófagos espumosos próximos a veia centrolobular (setas) e macrófagos isolados (cabeça de seta) no parênquima hepático, na intoxicação por Brachiaria decumbens em bovino. HE, obj.20x.

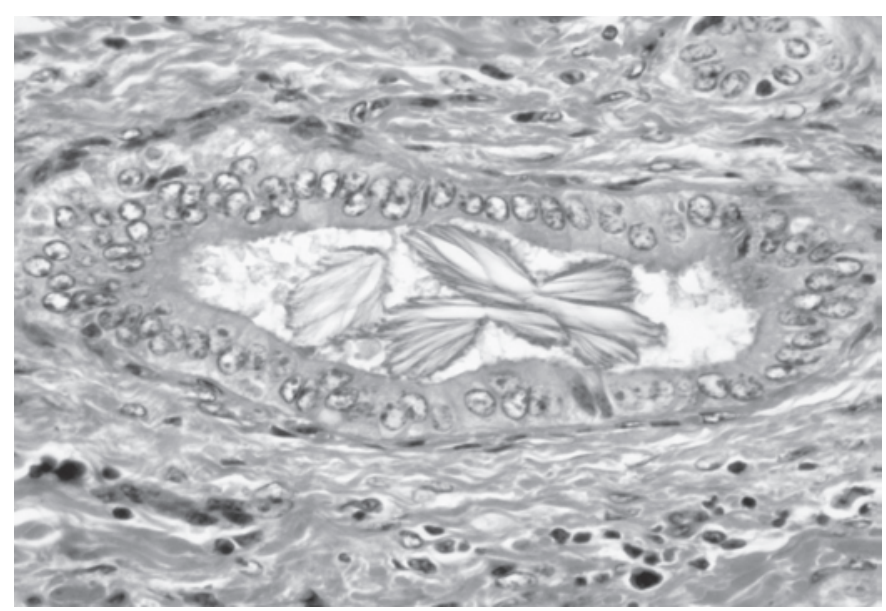

Fig.5. Cristais birrenfringentes na luz de um um ducto biliar, na intoxicação por Brachiaria decumbens em bovino. HE, obj.20x. biliares foram observados em animais de diversas idades, incluindo os bezerros lactentes.

\section{DISCUSSÃO}

A fotossensibilização causada por Brachiaria spp. é uma importante causa de prejuízos econômicos em bovinos do Mato Grosso do Sul. No entanto, é provável que a doença seja subnotificada uma vez que é bastante conhecida por proprietários e profissionais que acabam não enviando material para o laboratório de diagnóstico. Neste estudo retrospectivo o principal quadro clínico observado foi de fotossensibilização hepatógena, no entanto foram diagnosticados, também, cinco surtos de emagrecimento progressivo, semelhantes aos descritos anteriormente (Riet-Correa et al. 2002).

Os surtos ocorreram em 16 municípios em diferentes regiões do Mato Grosso do Sul, indicando que não existem variações regionais. Surtos de intoxicação foram diagnosticados em praticamente todos os meses dos anos, em maior número nos meses de junho e julho. Fagliari et al. (1993a) também observaram a intoxicação em todos os meses do ano, tanto na seca quanto na chuva. Diversos fatores têm sido responsabilizados pela ocorrência de surtos de intoxicação por Brachiaria spp., entre eles a colocação de animais em pastagens vedadas (sem pastejo por um período de alguns meses) e após as primeiras chuvas, coincidindo com a brotação das pastagens (Lemos et al. 1997). Este trabalho demonstra que a intoxicação por Brachiaria spp. em bovinos ocorre em todos os meses do ano, não havendo maior incidência na época da brotação das pastagens, após as primeiras chuvas, que na região ocorrem em outubro-novembro. No entanto, não foi estudada a provável relação dos surtos com chuvas mais ou menos recentes, mesmo na época da seca, que poderiam ter induzido o rebrote das pastagens. Por outro lado, a ocorrência da doença em pastagens vedadas pode ser devida a fatores outros que a maior toxicidade das mesmas. Em um surto ocorrido durante o ano 1994 foram afetados 30 bezerros de um grupo de 1600 , que tinham sido introduzidos numa pastagem vedada, provenientes de uma área do pantanal Sul-matogrossense onde não havia Brachiaria spp. (Lemos et al.1997). Nesse surto o fator determinante poderia ter sido a introdução de animais em pastagens vedadas, mas um fator, provavelmente mais importante, foi o fato dos animais serem provenientes de áreas sem Brachiaria spp. Em ovinos foi comprovado que animais criados em pastagens de Brachiaria spp. são mais resistentes à intoxicação que ovinos criados em outras pastagens (Castro et al. 2007). Não se sabe se essa resistência é hereditária ou adquirida (Castro et al. 2009), mas há evidências de que a mesma é hereditária e que ovinos susceptíveis não se tornam resistentes pelo pastejo em pastagens de Brachiaria spp (Aniz et al. 2008). Tem sido relatado que a intoxicação ocorre principalmente quando bezerros desmamados são introduzidos em pastos vedados (Riet-Correa et al. 2009). Essa situação pode estar associada ao manejo empregado no Mato Grosso do Sul, pois é uma prática comum reservar uma área de pastagem 
no período chuvoso para os bezerros desmamados serem introduzidos por ocasião da desmama, o que coincide com o início do período seco. Nessas condições é provável que a intoxicação ocorra pelo fato de introduzir nas pastagens bezerros recentemente desmamados, submetidos a estresse, e não ao fato das pastagens serem mais tóxicas que as pastagens de origem dos animais antes da desmama. A época do desmame coincide com o início da estação seca do ano, em junho e julho. Embora a não adaptação dos animais ao consumo da planta seja uma condição associada à ocorrência da intoxicação (Riet-Correa et al. 2009), a maioria dos surtos diagnosticados neste estudo ocorreram em rebanhos criados $B$. decumbens.

Neste trabalho não foram determinados os níveis de saponinas nas pastagens que ocasionaram os surtos. Entretanto, alguns autores descrevem maiores concentrações de saponinas no período de queda das sementes, ou seja, no final do período vegetativo da planta (Brum et al. 2009), enquanto outros relatam que a planta na rebrota é mais tóxica e apresenta teores de saponinas mais elevados (Santos Júnior 2008). Em outro estudo os maiores níveis de saponina foram encontrados nas folhas jovens, mas fatores climáticos como irradiação solar, temperatura ambiente e diferentes fases de crescimento da forrageira estiveram associados a variações nos níveis de saponinas (Barbosa-Ferreira et al. 2009).

Dos 24 surtos de fotossensibilização, 11 aconteceram em pastagens de $B$. decumbens, dois em pastos mistos de $B$. decumbens e $B$. brizantha, um em pastagens de $B$. brizantha e em 10 foi informado que a pastagem era de Brachiaria, sem informar a espécie. Até o momento não existem estudos comparativos que determinem a diferente toxicidade entre as espécies de Brachiaria spp. No entanto, considerando que no Centro-Oeste há cerca $30 \mathrm{mi}-$ Ihões de hectares de $B$. brizantha e 15 milhões de hectares de $B$. decumbens (Macedo et al. 2005) é evidente que a intoxicação é mais freqüente em $B$. decumbens do que em $B$. brizantha. Na literatura a grande maioria dos surtos de intoxicação em bovinos é causada, também, por $B$. decumbens (Camargo et al. 1976, Döbereiner et al. 1976, Nobre \& Andrade 1976, Fagliari et al. 1983, 1993b, Lemos et al. 1997). Surtos de intoxicação por B. brizantha são raros (Schenk \& Schenk 1983).

Bovinos de diversas faixas etárias foram afetados, com exceção de animais entre 25-30 meses de idade. A maioria dos surtos foi em bovinos de 7-12 meses. Estes resultados concordam com outros relatos que mencionam que a maioria dos surtos de fotossensibilização em $B$. decumbens ocorrem em bovinos de até 2 anos de idade, que são mais susceptíveis (Döbereiner et al. 1976, Fagliari et al. 1993, Tokarnia et al. 2000). Chama atenção a ocorrência de um surto em bezerros de 30-60 dias o que sugere a possibilidade de que as saponinas esteroidais sejam eliminadas pelo leite. Um surto semelhante foi descrito anteriormente em bezerros de 15-40 dias(Fagliari et al. 1983).

A frequência da intoxicação foi muito variável, semeIhante a descrições anteriores da enfermidade que descre- vem morbidade de $4,7 \%$ a $56,2 \%$ e letalidade de $2,7 \%$ a $35,5 \%$ (Garcia 1982, Fagliari et al 1993, Lemos et al. 1997). Os fatores que determinam essa variação, incluindo variações de toxicidade de diferentes espécies e variedades de Brachiaria, variações nas concentrações de saponinas na planta associados a mudanças climáticas ou de manejo, e diferenças na resistência/susceptibilidade entre animais de diferente idade, raça ou procedência devem ser melhores estudadas, para estabelecer medidas mais eficientes de profilaxia e controle.

O sinal clínico mais freqüente foi o edema de barbela, isto por que os casos mais agudos morrem sem chegar a apresentar dermatite. Esse e outros sinais clínicos observados são semelhantes aos descritos anteriormente (Fagliari et al. 1993b, Fiorante 1999, Tokarnia et al. 2000, Riet-Correa et al. 2009) e podem ser confundidos com os observados em casos de fotossensibilização causados por outras plantas, incluindo Enterolobium contortisiliquuum, Stryphnodendron fissuratum, S. obovatum, Lantana spp e Pterodon emarginatus (Ferreira et al. 2009, Riet-Correa et al. 2009). Em bezerros lactentes ou recentemente desmamados, filhos de vacas Nelore, as lesões de pele na intoxicação por Brachiaria spp podem ser muito semelhantes às observadas em casos de dermatofilose, que se caracterizam por formação de crostas ao redor dos olhos e do focinho e intenso lacrimejamento; no entanto, na dermatofilose não há retração cicatricial das pontas das orelhas como ocorre na fotossensibilização (Lemos et al. 2008). A dermatofilose geralmente ocorre em forma de surtos em pastagens formadas predominantemente por $B$. brizantha, com morbidade de $5-25 \%$ e está relacionada com chuvas fortes e constantes, que alem da umidade contribuem para o estresse e a conseqüente baixa da imunidade dos bovinos (Lemos et al. 2008).

Dois casos apresentaram manifestações clínicas neurológicas associadas a sinais da fotossensibilização. Sinais nervosos, atribuídos à encefalopatia hepática, foram descritos em ovinos por Salam-Abdullah et al (1989). No único surto em que foi observado diarréia, o bovino examinado apresentou lesões de eimeriose, macrófagos espumosos e cristais birrefringentes. Neste caso a diarréia pode não ser associada a um efeito tóxico da Brachiaria sp. No entanto, é possível, também, que as lesões da intoxicação por Brachiaria tenham ocasionado estresse ou depressão imunológica que favoreceram a infecção por Eimeria sp., doença que não é freqüente na faixa etária do rebanho afetado(1 ano e meio).

Nos casos que cursaram com fotossensibilização hepatógena, as principais alterações macroscópicas foram hepatomegalia, fígado amarelado e/ou com padrão lobular aumentado, ulcerações na parte ventral da língua, rins acastanhados, urina escura e fígado com áreas esbranquiçadas deprimidas. Estas alterações variam de intensidade e freqüência o que está relacionado à evolução clínica, mas são semelhantes às relatadas anteriormente (Camargo et al. 1976, Lemos et al. 1997, Tokarnia et al. 2000, Riet-Correa et al. 2009). 
As lesões histológicas observadas nos casos de fotossensibilização descritos neste trabalho são semelhantes às descritas por outros autores (Döbereiner et al. 1967, Driemeier et al. 1998, Lemos et al. 1997, Tokarnia et al. 2000). Dessas lesões algumas são importantes para confirmar o diagnóstico da enfermidade, principalmente a tumefação difusa e necrose individual de hepatócitos e a presença de cristais birefringentes ou imagens negativas dos mesmos nos ductos biliares. No entanto, deve ser ressaltado que os cristais, que não são descritos em casos subclínicos de intoxicação por Brachiaria spp., não aparecem em todos os casos clínicos da mesma, portanto, a sua ausência não descarta a intoxicação. Por outro lado a observação de macrófagos espumosos no parênquima hepático é um achado incidental freqüente em animais sadios, criados em pastagens de Brachiaria spp., abatidos (Fioravante et al. 1999) ou mortos por outras doenças (Driemeier et al. 1999); isso significa dizer que somente a presença dos macrófagos espumossos não é suficiente para o diagnóstico da intoxicação por Brachiaria spp.

Três surtos de emagrecimento progressivo ocorreram em bovinos com idade superior a 24 meses e dois em bovinos de 7-12 meses. No único relato anterior de emagrecimento progressivo associado à ingestão de $B$. decumbens os bovinos tinham acima de dois anos (RietCorrea et al. 2002). Maiores estudos são necessários para determinar a epidemiologia desta forma de intoxicação por $B$. decumbens e sua provável relação com a ingestão de saponinas litogênicas. O principal achado de necropsia foi fígado amarelado conforme descrito por Riet-Correa et al. (2002). Esses autores atribuem a perda de peso à síndrome da má absorção associada à presença de macrófagos espumosos na submucosa intestinal. No presente estudo não foram observadas lesões intestinais; no entanto, somente foram examinadas histologicamente amostras do intestino de dois animais e não representativas de todo o intestino. Em todos os casos de emagrecimento progressivo havia lesões hepáticas características das causadas pela ingestão de Brachiaria spp., incluindo a presença de cristais, que anteriormente era relatada apenas em casos associados à fotossensibilização.

Agradecimentos.- Aos Técnicos de Laboratório de Anatomia Patológica da FAMEZ e aos colegas do Setor de Patologia Veterinária, pela valiosa ajuda deste trabalho. À Coordenação de Aperfeiçoamento de Pessoal de Nível Superior (CAPES), pela concessão de bolsa de mestrado, e ao Conselho Nacional de Desenvolvimento Científico e Tecnológico (CNPq), pelo auxílio à pesquisa.

\section{REFERÊNCIAS}

Aniz A.C.M. 2008. Efeito da adaptação do consumo de Brachiaria decumbens e a existência de resistência individual em ovinos à intoxicação. Trabalho de conclusão de curso, Faculdade de Medicina Veterinária e Zootecnia, Universidade Federal do Mato Grosso do Sul. 31p.

Barbosa M.F., Brum K.B., Fernandes C.E., Martins C.F., Monteiro L.C. Vandeufrazio S.C., Rezende K.G., Riet-Correa F., Haraguchi M., Junior H.L.W. \& Lemos R.A.A. 2009. Variations of saponin level $x$ maturation in Brachiaria brizantha leaves. $8^{\text {th }}$ International Sym- posium on Poisonous Plants. João Pessoa, Paraíba, Brazil, p.13. (Abstract)

Brum K.B., Haraguchi M., Lemos R.A.A., Riet-Correa F. \& Fioravante M.C. 2007.Crystal associated cholangiopathy in sheep grazing Brachiaria decumbens containing the saponin protodioscin. Pesq. Vet. Bras. 27:39-42.

Brum K.B., Haraguchi M., Garutti M.B., Nóbrega F.N., Rosa B. \& Fioravanti M.C.S. 2009. Steroidal saponin concentrations in Brachiaria decumbens and $B$. brizantha at diferent develomental stages. Ciência Rural 39:279-281.

Camargo W.V.A., Nazário W., Fernandes N.S. \& Amaral R.E.M. 1976. Fotossensibilização em bovinos de corte. Provável participação do fungo Pithomyces chartarum na etiologia do processo. Biológico 42: 249-261.

Castro M.B., Moscardini A.R.C., Reckziegel G.C., Novaes E.P.F., Mustafa V.S., Paludo G.R., Borges J.R.J. \& Riet-Correa, F. 2007. Susceptibilidade de ovinos a intoxicação por Brachiaria decumbens. $\mathrm{V}$ Congresso Latinoamericano de Especialistas em Pequeños Ruminantes y Camélidos Sudamericanos. Buenos Aires, Argentina s/p. (Abstract)

Castro M.B., Santos Jr H.L., Mustafa V.S., Gracindo C.V., Moscardini A.C.R., Louvandini H., Paludo G.R., Borges J.R.J., Haraguchi M., Ferreira M.B. \& Riet-Correa F. 2009. Brachiaria spp. poisoning in sheep in Brazil: Experimental and epidemiological findings. $8^{\text {th }}$ International Symposium on Poisonous Plants. João Pessoa, Paraíba, Brazil. p.12. (Abstract)

Cruz C., Driemeier D., Pires V.S., Colodel E.M., Taketa A.T.C. \& Schenkel E.P. 2000. Isolation of steroidal sapogenins implicated in experimentally induced cholangiopathy of sheep grazing Brachiaria decumbens in Brazil. Vet. Human Toxicol. 42:142-145.

Cruz C., Driemeier D., Pires V.S. \& Schenkel E.P. 2001. Experimentally induced cholangiopathy by dosing sheep with fractionated extracts from Brachiaria decumbens. J. Vet. Diag. Invest. 13:170-172.

Döbereiner J., Tokarnia C.H., Monteiro M.C., Cruz L.C.H., Carvalho E.C. \& Primo A.T. 1976. Intoxicação de bovinos e ovinos em pastos de Brachiaria decumbens contaminados por Pithomyces chartarum. Pesq. Agropec. Bras., Ser. Vet. 11:87-94.

Driemeier D., Barros S.S., Peixoto P.V., Tokarnia C.H., Döbereiner J. \& Brito M.F. 1998. Estudo histológico, histoquímico e ultra-estrutural de fígados e linfonodos de bovinos com presença de macrófagos espumosos ("foam cells"). Pesq. Vet. Bras. 18:29-34.

Driemeier D., Döbereiner J., Peixoto P.V. \& Brito M.F. 1999. Relação entre macrófagos espumosos ("foam cells") no fígado de bovinos e ingestão de Brachiaria spp. no Brasil. Pesq. Vet. Bras. 19:79-83.

Fagliari J.J., Passipieri M. \& Oliveira J.A. 1983. Sintomas de fotossensibilidade em bezerros alimentados com leite materno. Arq. Bras. Med.Vet. Zootec. 35:479-484.

Fagliari J.J., Okuda H.T., Kuchembuck M.R.G. \& Curi P.R. 1993a. Intoxicação natural de bovinos pela micotoxina esporidesmina. I. Aspectos epidemiológicos. Arq. Bras. Med. Vet. Zootec. 45:263-274

Fagliari J.J., Oliveira J.A., Kuchembuck M.R.G. \& Curi P.R. 1993b. Intoxicação natural de bovinos pela micotoxina esporodesmina. II. Aspectos clínicos. Arq. Bras. Med. Vet. Zootec. 45:275-282.

Ferreira E.V., Boabaid F.M., Arruda L.P., Lemos R.A.A., Souza M.A., Nakazato L. \& Colodel E.M. 2009. Intoxicação por Stryphnodendron fissuratum (Mimosoideae) em bovinos. Pesq. Vet. Bras. 29:951-957.

Fioravanti M.C. 1999. Incidência, avaliação clínica, laboratorial e anatomopatológica da intoxicação subclínica por esporidesmina em bovinos. Tese de Doutorado, Faculdade de Medicina Veterinária e Zootecnia, Unesp, Botucatu. 256p.

Graydon R.I., Hamid H. \& Zahari P. 1991. Photosensitization and crystal associated cholangiohepatopathy in sheep grazing Brachiaria decumbens. Aust. Vet. J. 68:234-236.

Lemos R.A.A. \& Leal C.R.B. 2008. Doenças de impacto econômico 
em bovinos de corte: perguntas e respostas. Ed. UFMS, Campo Grande/MS, p.232-236.

Lemos R.A.A., Salvador S.C. \& Nakazato L. 1997. Photosensitization and crystal associated cholangiohepatopathy in cattle grazing Brachiaria decumbens in Brazil. Vet. Human Toxicol. 39:376-377.

Macedo M.C.M. 2005. Pastagens no Ecossitema Cerrados: evolução das pesquisas para o desenvolvimento sustentável. Anais $42^{a}{ }^{a}$ Reun. Anu. Soc. Bras. Zootecnia, Goiânia, p.56-84.

Nobre D. \& Andrade S.O. 1976. Relação entre fotossensibilização em bovinos jovens e a gramínea Brachiaria decumbens Stapf. Biológico, São Paulo, 42:249-258.

Riet-Correa G., Riet-Correa F., Schild A.L. \& Driemeier D. 2002. Wasting and death in cattle associated with chronic grazing of Brachiaria decumbens. Vet. Hum. Toxicol. 44:179-180.
Riet-Correa F., Medeiros R.M.T., Pfister J., Schild A.L. \& Dantas A.F.M. 2009. Poisonings by plants, mycotoxins and related substances in Brazilian livestock, Pallotti, Santa Maria, p.80-89.

Santos Jr H.L. 2008. Estudo da toxicidade de diferentes estágios de crescimento de Brachiaria decumbens em ovinos. Dissertação de Mestrado em Saúde Animal, FAV-UnB, Brasília. 70p.

Salam-Abdullah A.S., Noordin M.M. \& Rajion M.A. 1989. Neurological disorders in sheep during signal grass (Brachiaria decumbens) toxicity. Vet. Hum. Toxicol. 31:128-129.

Shenk M.A.M. \& Shenk J.A.P. 1983. Fotossensibilização em bovinos: aspectos gerais. Comunicado Técnico no 19, Embrapa. 4p.

Tokarnia C.H., Döbereiner J. \& Peixoto P.V. 2000. Pithomyces chartarum/Brachiaria spp, p.164-175. In: Ibid. (Eds), Plantas Tóxicas do Brasil. Editora Helianthus, Rio de Janeiro. 